\title{
Análise do Papel de Variáveis Sociais e de Conseqüências Programadas no Seguimento de Instruções
}

\author{
Niele Márcia Amaral de Albuquerque ${ }^{1}$ \\ Carla Cristina Paiva Paracampo ${ }^{2}$ \\ Luiz Carlos de Albuquerque \\ Universidade Federal do Pará
}

\begin{abstract}
Resumo
Investigando o papel da monitorização no seguimento de instruções, 12 crianças foram expostas a um procedimento de escolha segundo o modelo. A tarefa era tocar um dos dois estímulos de comparação na presença de um estímulo contextual. As respostas corretas evitavam e as incorretas produziam perda de reforçadores. O experimento consistia de cinco fases. As Fases 1, 3 e 5 eram iniciadas com uma instrução correspondente às contingências; as contingências em vigor na Fase 1 eram revertidas na Fase 2, restabelecidas na Fase 3, novamente revertidas na Fase 4 e restabelecidas na Fase 5. Os participantes foram atribuídos a duas condições, que diferiam quanto à fase na qual um observador era introduzido na situação experimental. Observou-se que 10 participantes abandonaram o seguimento de instruções nas Fases 2 e 4. Sugere-se que, mesmo quando é monitorado, o seguimento de instruções tende a deixar de ocorrer quando produz perda de reforçadores.

Palavras-chave: Comportamento governado por regras; monitorização; perda de reforçadores; procedimento de escolha segundo o modelo; crianças.
\end{abstract}

\section{Analyzing the Role of Social Variables and Programmed Consequences in Instruction-Following}

\begin{abstract}
Twelve children in the eight-to-nine year age range were exposed to a matching-to-sample procedure in an investigation dealing with the role of monitoring in instruction-following. On this task, two comparison stimuli were touched in the presence of a contextual stimulus. Whereas incorrect responses resulted in reinforcement loss, correct responses avoided this consequence. There were five phases in the experiment: Phases 1, 3 and 5 began with an instruction corresponding to the contingencies; contingencies in effect in Phase 1 were reversed in Phase 2, reestablished in Phase 3, reversed again in Phase 4 and renewed in Phase 5. The participants were subjected to two conditions, differing with regard to the phase where an observer was introduced in the experimental situation. During Phases 2 and 4, 10 participants did not follow instructions. This finding indicates that even when monitoring is present, instruction-following does not occur if it is not reinforced.

Keywords: Rule-governed behavior; monitoring; reinforcement loss; matching-to-sample; children.
\end{abstract}

Os estudos que têm comparado os efeitos de instruções com os efeitos de contingências de reforço têm mostrado, em geral, que instruções podem exercer forte controle sobre o comportamento humano. Por exemplo, Lippman e Meyer (1967) expuseram humanos adultos a um esquema de intervalo fixo $20 \mathrm{~s}$ (FI $20 \mathrm{~s}$ ) e observaram que os participantes que foram inicialmente expostos a instruções (correspondentes) que especificavam que o reforço estaria disponível de acordo com um esquema de FI, apresentaram baixa taxa de respostas e a curva típica de FI. Já os participantes que foram inicialmente expostos a instruções (discrepantes) que especificavam que o reforço

\footnotetext{
${ }^{1}$ Este trabalho foi baseado nos dados da dissertação de mestrado do primeiro autor apresentada em 2002 no Programa de Pós-Graduação em Teoria e Pesquisa do Comportamento/UFPA, e foi realizado com o auxílio financeiro da CAPES em forma de bolsa concedida ao primeiro autor.

${ }^{2}$ Endereço para correspondência: Rua Oliveira Belo, 238/1702, 66050380 , Umarizal, Belém, PA. (91) 2238995.E-mail:ccpp@cpgp.ufpa.br
}

estaria disponível de acordo com um esquema de razão, apresentaram um padrão de taxa alta de respostas; e os participantes que foram expostos apenas a instruções mínimas, apresentaram ou um padrão de taxa alta ou um padrão de taxa baixa de respostas.

Estes resultados, juntos com resultados similares encontrados em outros estudos (Baron, Kauffman \& Stauber, 1969; Galizio, 1979; Weiner, 1970) sugerem que instruções correspondentes (aquelas que correspondem às reais contingências em efeito) podem estabelecer a forma inicial do comportamento e gerar desempenhos de acordo com as contingências de reforço programadas. Em contraste, instruções discrepantes das contingências (aquelas que não correspondem às reais contingências em efeito) podem interferir com o controle exercido pelas contingências de reforço e gerar comportamento que apresenta mais as características das contingências de reforço que foram descritas do que das contingências de reforço programadas (Baron \& Galizio, 1983). 
A partir desses primeiros estudos, alguns trabalhos nessa linha de pesquisa começaram a investigar as condições sob as quais o seguimento de instruções é mais ou menos provável de ser mantido (Albuquerque \& Ferreira, 2001). Por exemplo, tem sido mostrado que, quando instruções correspondem às contingências de reforço programadas no experimento, o comportamento de seguir instrução pode ser mantido indefinidamente (Hayes, Brownstein, Zettle, Rosenfarb \& Korn, 1986; Joyce \& Chase, 1990; LeFrancois, Chase \& Joyce, 1988; Paracampo, 1991; Paracampo, Souza, Matos \& Albuquerque, 2001). Entretanto, quando instruções são discrepantes dessas contingências, o comportamento de seguir instruções pode tanto ser mantido, quanto deixar de ocorrer (Albuquerque, 1998; Galizio, 1979; Hayes \& cols., 1986; Shimoff, Catania \& Matthews, 1981).

As condições sob as quais o comportamento de seguir instruções discrepantes das contingências é mais ou é menos provável de ser mantido ainda não estão claramente identificadas na literatura. Por exemplo, alguns estudos têm sugerido que o comportamento de seguir instruções discrepantes tende a deixar de ocorrer quando é antecedido por condições que geram variação comportamental (Chase \& Danforth, 1991; Joyce \& Chase, 1990; LeFrancois \& cols., 1988). Contudo, há evidências mostrando que este comportamento pode ser mantido, mesmo quando antecedido por uma história de variação comportamental (Paracampo \& cols., 2001). Do mesmo modo, há tanto evidências que apóiam a proposição que sugere que o seguimento de instruções discrepantes tende a ser mantido quando as contingências são fracas (Cerutti, 1989), isto é, quando não se demonstra controle discriminativo pelas contingências de reforço antes da apresentação de uma instrução ao ouvinte (Torgrud \& Holborn, 1990), quanto há evidências que limitam a generalidade dessa proposição (Albuquerque, 1998).

Apesar dessas controvérsias, também há consenso na literatura. Grande parte dos autores, por exemplo, concorda que o comportamento de seguir instruções discrepantes das contingências tende a deixar de ocorrer quando mantém contato prolongado com conseqüências que contradizem a própria instrução (Baron \& Galizio, 1983; Bernstein, 1988; Michael \& Bernstein, 1991; Galizio, 1979; Hayes \& cols., 1986; Shimoff \& cols., 1981) e quando produz perda de reforçadores (Baron \& Galizio, 1983; Chase \& Danforth, 1991; Galizio, 1979; LeFrancois \& cols., 1988; Paracampo, Albuquerque \& Fontes, 1993; Perone, Galizio \& Baron, 1988).

Alguns autores também concordam que o comportamento de seguir instruções discrepantes das contingências tende a ser mantido quando o comportamento especificado pela instrução é monitorado por membros da comunidade verbal identificados como "autoridades", tais como policiais, parentes, professores, patrões, médicos, etc (Albuquerque, 1998; Barret, Deitz, Gaydos \& Quinn, 1987; Capovilla \& Hineline, 1989; Cerutti, 1989; Hayes \& cols., 1986).

Evidências de que a manutenção do seguimento de instruções depende, em parte, do tipo de conseqüência que produz, podem ser encontradas, por exemplo, no estudo de Galizio (1979). Este autor conduziu experimentos de esquiva múltipla, nos quais investigou o controle instrucional e do esquema de reforço, quando instruções estavam ou não de acordo com o esquema. Os componentes do esquema múltiplo eram FI 10 s, FI 30 s, FI $60 \mathrm{~s} \mathrm{(de} \mathrm{perda} \mathrm{de} \mathrm{pontos}$ trocáveis por dinheiro) e não perda (isto é, quando o componente era de extinção). A tarefa dos estudantes universitários era girar uma alavanca, o que evitava a perda de pontos de acordo com o esquema de FI em vigor. $\mathrm{Na}$ primeira fase, a introdução de instruções que correspondiam ao esquema em efeito levou a um rápido controle do esquema sobre o comportamento. $\mathrm{Na}$ segunda fase, quando as contingências foram alteradas (sem sinalização) para uma condição de não perda em todos os componentes do esquema, os participantes continuaram seguindo as instruções, previamente apresentadas no início da Fase 1. $\mathrm{Na}$ terceira fase, quando as contingências foram novamente alteradas para um esquema de FI $10 \mathrm{~s}$ em todos os componentes do esquema múltiplo e os participantes mantiveram contato com a discrepância instrução/esquema (isto é, quando o seguimento de instrução passou a produzir perda de pontos trocáveis por dinheiro), o seguimento de instrução deixou de ocorrer e todos os quatro participantes passaram a responder de acordo com as contingências programadas. $\mathrm{Na}$ quarta fase, quando as contingências em vigor na Fase 2 (não perda em todos os componentes) foram re-introduzidas, o desempenho de três dos quatro participantes mudou acompanhando as mudanças nas contingências, ou seja, o controle instrucional não foi restabelecido. Galizio concluiu que o comportamento de seguir instrução pode ser mantido após mudanças nas contingências, quando não mantém contato com a discrepância instrução/contingências. Quando o seguir instrução mantém contato com a discrepância instrução/ contingências (isto é, quando o comportamento de seguir instrução mantém contato com as conseqüências que contradizem a própria instrução), é provável que ele mude acompanhando as mudanças nas contingências.

Paracampo e colaboradores (1993) encontraram resultados que sustentam essa proposição. Nesse estudo, quatro crianças foram expostas a um procedimento de escolha segundo o modelo. $\mathrm{O}$ experimento era constituído de três fases. No início do experimento, o experimentador apresentava instruções correspondentes que especificavam 
o que o participante deveria fazer para não perder moedas trocáveis por brinquedos. As respostas dos participantes eram registradas por uma filmadora e por um observador, que ficava próximo ao experimentador durante todo o experimento. $\mathrm{Na}$ Fase 1, uma luz verde indicava que o participante deveria apontar para o estímulo de comparação igual ao estímulo modelo e uma luz vermelha indicava que deveria apontar para o estímulo de comparação diferente do estímulo modelo e nenhuma resposta era conseqüenciada com perda de moedas nesta fase. $\mathrm{Na}$ Fase 2 , as contingências eram alteradas, isto é, as respostas ao estímulo de comparação igual ao estímulo modelo na presença da luz verde passavam a ser conseqüenciadas com a retirada de uma moeda. Nenhuma outra resposta emitida pelos participantes nesta fase produzia perda de moedas. $\mathrm{Na}$ Fase 3 as contingências eram novamente alteradas com o retorno às contingências em vigor na Fase 1. Todos os quatro participantes seguiram a instrução na Fase 1. Entretanto, todos os participantes abandonaram o seguimento de instrução na Fase 2 (isto é, três participantes passaram a escolher o diferente na presença da luz verde e o igual na presença da luz vermelha e um passou a escolher o diferente independentemente das luzes) e continuaram respondendo de acordo com as contingências de reforço na Fase 3. Os autores concluíram que o seguimento de instrução tende a deixar de ocorrer quando produz perda de reforçadores.

Quanto às evidências dos efeitos da monitorização do seguimento de instruções, estas podem ser encontradas em vários estudos (Barret \& cols., 1987; Capovilla \& Hineline, 1989; Cerutti, 1994; Hayes \& cols., 1985; Hayes \& Wolf, 1984; Peterson, Merwin, Moyer \& Whitehurst, 1971; Rosenfarb \& Hayes, 1984; Zettle \& Hayes, 1983). Por exemplo, Barret e colaboradores (1987) realizaram um estudo objetivando investigar os efeitos da monitorização (presença versus ausência do experimentador durante a realização da tarefa experimental) sobre o comportamento de seguir instruções. Para tanto, expuseram vinte participantes a uma tarefa experimental que consistia em mover uma luz do canto superior esquerdo ao canto inferior direito de uma matriz, pressionando quatro chaves. Os participantes foram alocados a uma de duas condições experimentais. Cada condição era constituída de três fases. Na primeira condição, o experimentador permanecia na sala próximo ao participante, observando o seu desempenho, sem interferir na realização da tarefa. Na segunda condição, o participante ficava sozinho na sala, realizando a tarefa. A Fase 1 consistia na modelagem de um padrão de respostas idênticas e consecutivas que deveria ser emitido duas vezes para que um reforço (pontos trocáveis por dinheiro) fosse concedido. $\mathrm{Na}$ Fase 2 era introduzida uma instrução correspondente que especificava que os participantes deveriam produzir um padrão de respostas diferente a cada tentativa para que o reforço fosse concedido. Na Fase 3, as contingências de reforço eram alteradas, com o retorno às contingências em vigor na Fase 1. $\mathrm{Na}$ Fase 1, os participantes das duas condições apresentaram o padrão de respostas modelado. $\mathrm{Na}$ Fase 2, os participantes das duas condições seguiram a instrução correspondente, isto é, passaram a apresentar padrões variados de respostas. $\mathrm{Na}$ Fase 3 , a maioria dos participantes da condição que tinha o experimentador presente continuou apresentando um padrão variado de respostas, conforme especificado pela instrução correspondente no início da Fase 2. Ou seja, os desempenhos dos participantes não mudaram acompanhando as mudanças nas contingências de reforço. Já a maioria dos participantes da condição com o experimentador ausente, durante a Fase 3, voltou a emitir padrões de respostas idênticas e consecutivas, de acordo com as contingências em vigor nesta fase. Ou seja, os desempenhos dos participantes mudaram acompanhando as mudanças nas contingências de reforço. Os autores sugeriram que é mais provável que o seguimento de instrução seja mantido na presença do experimentador do que na sua ausência.

Os estudos que têm investigado os efeitos da monitorização da tarefa não se limitam apenas a manipular a presença versus a ausência do experimentador. Por exemplo, Cerutti (1994) comparou os desempenhos, verbal e não verbal, de estudantes universitários, quando os seus desempenhos eram monitorados, ou não, por uma câmera de vídeo. $\mathrm{O}$ comportamento não verbal reforçado era o de pressionar botões de acordo com um esquema múltiplo FI 10 s / FI 10 s. O comportamento verbal reforçado era o de completar sentenças do tipo "a melhor maneira de pressionar o painel da esquerda é...”, selecionando uma das seguintes alternativas de respostas: a) "devagar"; b) "muito devagar"; c) "moderadamente devagar"; d) "rápido"; e) "muito rápido"; f) "moderadamente rápido". Ao longo do experimento, as contingências de reforço programadas para o comportamento verbal eram revertidas três vezes, enquanto as contingências para o comportamento não verbal permaneciam inalteradas. Deste modo, as respostas verbais ora correspondiam, ora não correspondiam às contingências de reforço programadas para o comportamento não verbal. O desempenho não verbal dos participantes expostos à condição de monitorização da tarefa correspondeu ao desempenho verbal modelado durante todo o experimento, independente das contingências de reforço programadas para o não verbal. Já o desempenho não verbal dos participantes expostos à condição de não monitorização deixou de corresponder ao desempenho verbal modelado ao longo do experimento. $\mathrm{O}$ autor concluiu que a monitorização da execução da tarefa experimental é 
uma variável relevante para gerar um responder não verbal de acordo com as formulações verbais.

Em síntese, esta análise das condições sob as quais o seguimento de instruções é mais ou é menos provável de ser mantido, sugere que o seguimento de instruções tende a ser mantido quando é monitorado e tende a deixar de ocorrer quando produz perda de reforçadores. Não está claro, no entanto, se o comportamento de seguir instruções discrepantes das contingências de reforço seria mantido ou não, caso este comportamento fosse tanto monitorado quanto produzisse perda de reforçadores, uma vez que nenhum dos estudos comentados até o momento foi planejado com o objetivo de investigar esta possibilidade. Nos estudos de Barret e colaboradores (1987) e Cerutti (1994), o seguimento de instruções era monitorado, mas não produzia perda de reforçadores, apenas deixava de produzir reforçadores. Já no estudo de Galizio (1979) o seguimento de instruções produzia perda de reforçadores, mas não era monitorado. No estudo de Paracampo e colaboradores (1993), no entanto, pode-se dizer que o seguimento de instruções produzia perda de reforçadores e era monitorado, uma vez que durante o experimento, o experimentador sentava-se de frente para o participante, apresentava as instruções, os arranjos de estímulos e reforçava diferencialmente com a retirada de fichas as respostas que eram registradas por um observador. Neste estudo, no entanto, não foram apresentadas instruções especificando que o desempenho dos participantes seria observado, isto é, monitorado pelo observador, nem a presença versus a ausência do observador foi manipulada.

Considerando isto, o presente estudo pretendeu investigar se o comportamento de crianças muda ou não acompanhando mudanças nas contingências de reforço programadas, quando, após as mudanças nas contingências: 1) a manutenção do comportamento de seguir instrução produz perda de reforçadores; e 2) a presença versus a ausência do observador, monitorando o seguimento de instruções, é manipulada.

\section{Método}

\section{Participantes}

Participaram do estudo 6 meninos (P12, P14, P16, P22, P23 e P26 ) e 6 meninas (P11, P13, P15, P21, P24 e P25), com idades variando entre 8 e 9 anos, cursando a segunda série do ensino fundamental em uma escola pública federal. De cada turma foram escolhidas, pela professora, no máximo duas crianças. As crianças de uma mesma turma sempre foram atribuídas a condições experimentais diferentes. Todas as crianças foram previamente autorizadas pelos responsáveis a participar da pesquisa através de um formulário de consentimento assinado pelos mesmos.

\section{Material}

Foi utilizada uma mesa retangular cujo tampo tinha uma abertura de 49,5 x 49,5cm, coberta por uma placa de acrílico leitoso, sob a qual ficavam quatro lâmpadas fluorescentes de 20 watts, duas de cor vermelha e duas de cor verde. Separando o experimentador do participante, sobre a mesa, havia um anteparo de madeira de $14 \mathrm{~cm}$ de altura e 69,5 cm de comprimento. Atrás do anteparo, do lado do experimentador, ficavam os arranjos de estímulos previamente preparados, e um conjunto de interruptores para o controle das lâmpadas fluorescentes. Na frente do anteparo, próximo ao participante, ficava um gravador de fita.

Foram utilizados como estímulos discriminativos e condicionais 45 desenhos coloridos de objetos conhecidos das crianças (Ex.: uma lua, uma meia, etc.). Estes desenhos de $5 \times 5 \mathrm{~cm}$ cada, eram impressos em cartões de cartolina que eram colados em folhas de papel cartão de 14 x $14 \mathrm{~cm}$, de maneira a formar 30 diferentes arranjos de estímulos. Cada arranjo de estímulo continha três cartões com desenhos; dois desenhos eram sempre iguais entre si e o terceiro era diferente. Um cartão contendo um dos desenhos iguais era colado no topo da folha (estímulo modelo) e os outros dois mais abaixo e lado a lado (estímulos de comparação). A combinação dos estímulos era aleatória, assim como a ordem de apresentação dos 30 arranjos. Como estímulos contextuais foram utilizadas lâmpadas coloridas acesas, e como estímulos reforçadores, fichas pretas que poderiam ser trocadas por brinquedos e guloseimas. Uma vasilha de plástico era utilizada pelo experimentador para guardar as fichas. A vasilha ficava sobre $\mathrm{o}$ anteparo ao lado direito do experimentador.

O desempenho dos participantes era registrado pelo experimentador em um protocolo de registro previamente preparado e era também gravado em vídeo e em fitas cassete, para análises posteriores.

O experimento foi realizado em uma sala da escola, medindo $48 \mathrm{~m}^{2}$. A sala estava equipada com um condicionador de ar e no teto estavam instaladas oito lâmpadas fluorescentes de 40 watts cada uma. Na sala, além da mesa experimental, havia uma mesa, visível ao participante, sobre a qual ficavam expostos diversos brinquedos e guloseimas. Em cada brinquedo e guloseima estava afixada uma etiqueta de papel com um número impresso (Ex.: 3, 10, 20 etc.), indicando o total de fichas que cada brinquedo e guloseima valia.

\section{Procedimento}

O participante era conduzido à sala experimental pelo experimentador, aproximadamente 5 minutos antes do início da sessão, quando lhe eram mostrados os brinquedos e guloseimas, e apresentadas, oralmente, as seguintes instruções iniciais: Eu te trouxe aqui para nós brincarmos de um jogo. No jogo 
nós temos esta lojinha com vários brinquedos. Estes brinquedos podem ser comprados com fichas como estas aqui (o experimentador mostrava cinco fichas ao participante). Por exemplo, este carrinho vale dez fichas, este chaveiro vale cinco fichas. No final do jogo você poderá ficar com muitas fichas e poderá vir aqui na lojinha e comprar brinquedos com as suas fichas. Quanto mais fichas você ficar, mais brinquedos você poderá comprar. Entendeu? (Esta instrução era repetida mais uma vez). Em seguida o experimentador dizia: Agora en vou te mostrar como se compra na lojinha. Eu vou te dar cinco fichas para você fazer uma compra na lojinha. Vamos ver o que você pode comprar com cinco fichas. Após o participante fazer a compra o experimentador dizia: Agora, vamos para aquela mesa que en vou te explicar como é o jogo. O participante e o experimentador se dirigiam à mesa experimental, com o participante levando o brinquedo e/ou guloseima que comprou e era dado início à sessão experimental.

No início da sessão experimental, que durava aproximadamente 40 minutos, participante e experimentador ficavam sentados à mesa, frente a frente. O experimentador apresentava oralmente ao participante uma instrução (descrita a seguir) e lhe entregava 100 fichas. Em seguida, passava a apresentar os arranjos de estímulos. Em cada tentativa, um arranjo constituído de um estímulo modelo e dois de comparação era apresentado ao participante e em seguida uma das lâmpadas era acesa. Na presença desses estímulos o participante deveria tocar com o dedo apenas um dos estímulos de comparação. Caso a reposta estivesse de acordo com as contingências programadas (resposta correta), nenhuma ficha era retirada do monte de fichas do participante, a lâmpada era apagada e o arranjo de estímulos retirado; caso a resposta fosse considerada incorreta, uma ficha era retirada do monte de fichas do participante, a lâmpada era apagada e o arranjo de estímulos retirado. Se o participante não respondesse, passados 5 segundos de sua apresentação, a luz era apagada e o arranjo retirado. Estas seqüências definiam uma tentativa. Entre uma tentativa e outra havia um intervalo variável de aproximadamente 5 segundos.

Os participantes foram alocados a uma de duas condições experimentais, como mostra a Tabela 1. Cada condição, realizada com seis participantes, era constituída de cinco fases e diferiram entre si apenas com relação à fase na qual o observador era introduzido na sessão experimental.

Tabela 1

Respostas de Escolha que Evitavam Perda de Fichas na Presença dos Estímulos Luzes, em cada uma das Cinco Fases das Condiçöes I e II do Experimento. Indica a Naturez̧a das Instruções Apresentadas no Início de cada Fase e a Presença ou Ausência do Observador nestas Fases

\begin{tabular}{|c|c|c|c|c|c|}
\hline Condições & Fases & $\begin{array}{c}\text { Natureza das } \\
\text { instruções }\end{array}$ & Observador & $\begin{array}{c}\text { Estímulos } \\
\text { luzes }\end{array}$ & $\begin{array}{c}\text { Respostas } \\
\text { corretas* }\end{array}$ \\
\hline \multirow{5}{*}{ Condição I } & 1 & Correspondente & Ausente & $\begin{array}{c}\text { Verde } \\
\text { vermelho }\end{array}$ & $\begin{array}{c}\text { Igual } \\
\text { diferente }\end{array}$ \\
\hline & 2 & $\begin{array}{l}\text { Tornam-se } \\
\text { discrepantes }\end{array}$ & Ausente & $\begin{array}{c}\text { Verde } \\
\text { vermelho }\end{array}$ & $\begin{array}{l}\text { Diferente } \\
\text { igual }\end{array}$ \\
\hline & 3 & Correspondente & Ausente & $\begin{array}{c}\text { Verde } \\
\text { vermelho }\end{array}$ & $\begin{array}{c}\text { Igual } \\
\text { diferente }\end{array}$ \\
\hline & 4 & $\begin{array}{l}\text { Tornam-se } \\
\text { discrepantes }\end{array}$ & Presente & $\begin{array}{c}\text { Verde } \\
\text { vermelho }\end{array}$ & $\begin{array}{l}\text { Diferente } \\
\text { igual }\end{array}$ \\
\hline & 5 & Correspondente & Ausente & $\begin{array}{c}\text { Verde } \\
\text { vermelho }\end{array}$ & $\begin{array}{c}\text { Igual } \\
\text { diferente }\end{array}$ \\
\hline \multirow[t]{5}{*}{ Condição II } & 1 & Correspondente & Ausente & $\begin{array}{c}\text { Verde } \\
\text { vermelho }\end{array}$ & $\begin{array}{c}\text { Igual } \\
\text { diferente }\end{array}$ \\
\hline & 2 & $\begin{array}{c}\text { Tornam-se } \\
\text { discrepantes }\end{array}$ & Presente & $\begin{array}{c}\text { Verde } \\
\text { vermelho }\end{array}$ & $\begin{array}{l}\text { Diferente } \\
\text { igual }\end{array}$ \\
\hline & 3 & Correspondente & Ausente & $\begin{array}{c}\text { Verde } \\
\text { vermelho }\end{array}$ & $\begin{array}{c}\text { Igual } \\
\text { diferente }\end{array}$ \\
\hline & 4 & $\begin{array}{l}\text { Tornam-se } \\
\text { discrepantes }\end{array}$ & Ausente & $\begin{array}{c}\text { Verde } \\
\text { vermelho }\end{array}$ & $\begin{array}{l}\text { Diferente } \\
\text { igual }\end{array}$ \\
\hline & 5 & Correspondente & Ausente & $\begin{array}{c}\text { Verde } \\
\text { vermelho }\end{array}$ & $\begin{array}{c}\text { Igual } \\
\text { diferente }\end{array}$ \\
\hline
\end{tabular}

Nota: A palavra igual representa a resposta de escolha do estímulo de comparação igual do modelo. A palavra diferente representa a resposta de escolha do estímulo de comparação diferente do modelo. 


\section{Condição I}

O objetivo desta condição foi o de verificar se o comportamento de seguir instruções, estabelecido através da apresentação de instruções correspondentes às contingências, muda ou não acompanhando mudanças nas contingências programadas, quando o comportamento de seguir instruções passa a produzir perda de fichas trocáveis por brinquedos e o desempenho do participante é monitorado por um observador.

Esta condição era constituída de cinco fases (ver Tabela 1). No início da Fase 1 o participante era exposto a instruções correspondentes (isto é, instruções que especificavam as respostas que evitavam a perda de fichas). $\mathrm{Na}$ Fase 2, as contingências de reforço em vigor na Fase 1 eram alteradas, passando-se a reforçar o comportamento oposto ao reforçado na fase anterior. Assim, na Fase 2 as instruções tornavam-se discrepantes das contingências e, portanto, o comportamento de segui-las passava a produzir perda de fichas. $\mathrm{Na}$ Fase 3, as instruções correspondentes eram reapresentadas, com o retorno às contingências em vigor na Fase 1 . $\mathrm{Na}$ Fase 4, as contingências eram revertidas novamente, com um retorno às contingências em vigor na Fase 2 ; era introduzido um observador na sessão experimental; e dito ao participante que o observador estava na sala para observá-lo jogando e anotar as suas respostas durante o jogo. Na Fase 5, as instruções correspondentes eram reapresentadas. Assim foi possível avaliar o efeito da monitorização da tarefa (presença versus ausência do observador) sobre o comportamento de seguir instrução em crianças. Segue-se a descrição das fases da Condição I.

\section{Fase 1}

A Fase 1 era iniciada com o experimentador apresentando as seguintes instruções correspondentes: $O$ jogo começa com você ganhando 100 fichas. Agora, en vou te dar 100 fichas (o experimentador entregava 100 fichas para o participante). $O$ objetivo do jogo é você não perder fichas para depois comprar brinquedos naquela lojinha. Você perde uma ficha cada vez, que eu tiro uma ficha do seu montinho e coloco na minha vasilha (no presente estudo todas as vezes que esta frase era dita o experimentador retirava uma ficha do monte do participante e a colocava em sua vasilha). Agora, eu vou te explicar o que você deve fazerpara não perder fichas. $\mathrm{O}$ experimentador apresentava ao participante um arranjo constituído de um cartão modelo e dois de comparação. Em seguida o experimentador apontava para o cartão modelo e dizia: Este é o cartão-mãe. Toque com o dedo o cartão-mãe. Depois, apontava para os dois cartões de comparação e dizia: Estes são os cartões-filhos. Toque com o dedo os cartões-filhos. Logo após, o experimentador acendia a luz verde e dizia: Quando a mesa ficar verde, você deve tocar com o dedo o filho que é igual à mãe. A mesa está verde, toque o filho que é igual à mãe. Após o participante tocar, o experimentador dizia: Fazendo isso, você não perderáfichas. Depois a luz verde era apagada, a luz vermelha acesa e era dito: Quando a mesa ficar vermelha, você deve tocar com o dedo o filho que é diferente da mãe. A mesa está vermelha, toque o filho que é diferente da mãe. Após o participante tocar, o experimentador dizia: Fazendo isso, você não perderá fichas. Estas instruções eram apresentadas mais uma vez ao participante e depois disso era solicitado ao participante que verbalizasse qual a tarefa que deveria desempenhar, fazendo-se as seguintes perguntas: Quando a mesa ficar verde, o que você deve fazerpara não perder fichas? Após o participante responder, era feita a outra pergunta: Quando a mesa ficar vermelha, o que você deve fazer para não perder fichas? Feito isto, o experimentador informava ao participante que não poderia mais conversar com ele durante o jogo.

Durante esta fase as respostas que evitavam a perda de fichas eram as respostas de apontar para o estímulo de comparação igual ao estímulo modelo quando a luz verde estivesse acessa e as respostas de apontar para o estímulo de comparação diferente do estímulo modelo quando a luz vermelha estivesse acesa (respostas consideradas corretas na Fase 1). As respostas consideradas incorretas eram conseqüenciadas com a perda de fichas trocáveis por brinquedos. Esta fase era encerrada após a apresentação de 20 tentativas. Na transição da Fase 1 para a Fase 2 nenhuma instrução era apresentada aos participantes. A transição era marcada apenas pela mudança nas contingências programadas.

Fase 2

Durante esta fase as respostas que evitavam a perda de fichas eram o oposto da Fase 1: apontar para o estímulo de comparação diferente do estímulo modelo quando a luz verde estivesse acesa e apontar para o estímulo de comparação igual ao estímulo modelo quando a luz vermelha estivesse acesa (respostas consideradas corretas na Fase 2). As respostas consideradas incorretas eram conseqüenciadas com perdas de fichas. Esta fase era encerrada após a apresentação de 20 tentativas. A transição da Fase 2 para Fase 3 era marcada pela reapresentação das instruções correspondentes.

\section{Fase 3}

A Fase 3 era iniciada com a apresentação das mesmas instruções correspondentes apresentadas no início da Fase 1, exceto pela omissão do seguinte trecho: "Este é o cartão-mãe. Toque com o dedo o cartão-mãe". Estes são os cartões-filhos. Toque com o dedo os cartões-filhos". Deste modo, as instruções apresentadas na Fase 3 eram as seguintes: Agora, eu vou repetir o que você deve fazer para não perder fichas. O objetivo do jogo é você não perder fichas para depois comprar brinquedos naquela lojinha. Você perde uma ficha cada vez que eu tiro uma ficha do seu montinho e coloco na minha vasilha. 
Agora, en vou te explicar o que você tem que fazerer para não perder fichas. O experimentador acendia a luz verde e dizia: Quando a mesa ficar verde você deve tocar com o dedo o filho que é igual à mãe. A mesa está verde, toque o filho que éigual à mãe. Após o participante tocar, o experimentador dizia: Fazendo isso, você não perderá fichas. Depois a luz verde era apagada, a luz vermelha acesa e era dito: Quando a mesa ficar vermelha, você deve tocar com o dedo o filho que é diferente da mãe. A mesa está vermelha, toque o filho que é diferente da mãe. Após o participante tocar, o experimentador dizia: Fazendo isso, você não perderá fichas.

Durante esta fase as respostas que evitavam perda de fichas eram as respostas de apontar para o estímulo de comparação igual ao estímulo modelo quando a luz verde estivesse acesa e as respostas de apontar para o estímulo de comparação diferente do estímulo modelo quando a luz vermelha estivesse acessa (respostas consideradas corretas na Fase 3). Respostas consideradas incorretas eram conseqüenciadas com perdas de fichas. Esta fase era encerrada após a apresentação de 20 tentativas. A transição da Fase 3 para a Fase 4 era marcada pela introdução do observador na sessão experimental e pela mudança nas contingências programadas.

\section{Fase 4}

Esta fase era iniciada com a entrada do observador na sala experimental. Em seguida o experimentador apresentava as seguintes instruções ao participante, referindo-se ao observador: Esse é o ... (era dito o nome do observador). Ele está aqui para observar você jogando e vai ficar anotando as suas respostas durante o jogo. O observador ficava sentado ao lado esquerdo da mesa experimental olhando para a criança, segurando um papel e uma caneta e anotando as respostas da criança.

Durante esta fase as respostas que evitavam a perda de fichas eram as respostas de apontar para o estímulo de comparação diferente do estímulo modelo quando a luz verde estivesse acessa e as respostas de apontar para o estímulo de comparação igual ao estímulo modelo quando a luz vermelha estivesse acesa (respostas consideradas corretas na Fase 4). Respostas consideradas incorretas eram conseqüenciadas com perdas de fichas. Esta fase era encerrada após a apresentação de 20 tentativas. No final desta fase, o observador se retirava da sala experimental. A transição da Fase 4 para a Fase 5 era marcada pela apresentação de instruções correspondentes.

\section{Fase 5}

A Fase 5 era iniciada com a reapresentação das mesmas instruções correspondentes apresentadas no início da Fase 3. Durante esta fase as respostas que evitavam perdas de fichas eram as respostas de apontar para o estímulo de comparação igual ao estímulo modelo quando a luz verde estivesse acessa e as respostas de apontar para o estímulo de comparação diferente do estímulo modelo quando a luz vermelha estivesse acesa. Respostas consideradas incorretas eram conseqüenciadas com a perda de fichas. Esta fase era encerrada após a apresentação de 20 tentativas.

Em todas as fases, quando uma luz estava acesa a outra estava apagada. As luzes vermelha e verde eram apresentadas aleatoriamente ao longo das tentativas, garantindo-se que as duas fossem apresentadas o mesmo número de vezes em cada fase.

Cada participante era exposto a uma única sessão, que era encerrada ao final da Fase 5. A sessão durava 40 minutos, aproximadamente. Ao término da sessão a criança era conduzida à lojinha e trocava as suas fichas por brinquedos. Depois de encerrada a sessão, um observador independente comparava o registro feito pelo experimentador com o registro feito pela filmadora. Caso houvesse 100\% de concordância entre os registros, os dados do participante eram considerados para análise. Caso contrário, eram descartados por erro do experimentador na condução da sessão. No presente estudo, nenhum dos dados coletados foi descartado por essa ou qualquer outra razão.

\section{Condição II}

A Condição II era idêntica à Condição I, exceto por uma única diferença. $\mathrm{Na}$ Condição II, o observador, ao invés de entrar na sala experimental na Fase 4, entrava nesta sala na Fase 2 e se retirava após o término desta fase. A Condição II foi realizada apenas com o objetivo de controlar efeitos de ordem e, portanto, era aplicada a seis participantes novos que não tinham sido expostos à Condição I.

\section{Resultados}

Todos os participantes verbalizaram corretamente a tarefa que deveriam desempenhar, quando foram solicitados a fazêlo no início do experimento.

Estava programado para serem apresentadas em cada fase 20 tentativas. Isto ocorreu para 10 dos 12 participantes (P11, P12, P13, P14, P15, P21, P22, P23, P24 e P26). No entanto, na Fase 2, os Participantes P16 e P25 foram expostos a 30 e 40 tentativas, respectivamente, porque nesta fase eles vinham apresentando um padrão de respostas bastante variável, ora emitindo respostas de acordo com as contingências programadas nesta Fase 2, ora de acordo com as instruções apresentadas no início da Fase 1. Dessa forma, na Fase 2 estes dois participantes foram expostos a um número maior de tentativas que os demais para verificar se os seus desempenhos se estabilizariam em um desses dois padrões. 
A Figura 1 apresenta a freqüência acumulada de respostas de seguimento de instruções (linhas cheias) e não seguimento de instruções (linhas tracejadas) emitidas pelos Participantes P11, P12, P13, P14, P15 e P16 nas cinco fases da Condição I do experimento. Observa-se que todos os seis participantes (P11, P12, P13, P14, P15 e P16) seguiram as instruções apresentadas no início da Fase 1, ou seja, escolheram o estímulo de comparação igual ao estímulo modelo na presença da luz verde e o estímulo de comparação diferente do estímulo modelo na presença da luz vermelha. Nessa fase, quatro participantes (P11, P14, P15 e P16) emitiram respostas incorretas e, portanto, fizeram contato com a perda de fichas. O Participante P11 emitiu uma resposta incorreta na primeira tentativa, o que produziu a perda de uma ficha. Da segunda tentativa em diante passou a emitir respostas corretas de acordo com as especificadas na instrução no início da fase. Já o Participante P14, iniciou a Fase 1 seguindo instruções, emitindo respostas corretas na primeira e na segunda tentativa, mas na terceira, quarta e quinta tentativas emitiu respostas incorretas. Da sexta tentativa em diante voltou a emitir respostas corretas. O Participante P15 iniciou esta fase seguindo a instrução, mas emitiu respostas incorretas na segunda e na quarta tentativa. O Participante P16 só respondeu incorretamente na segunda tentativa, nas demais tentativas desta fase respondeu corretamente.
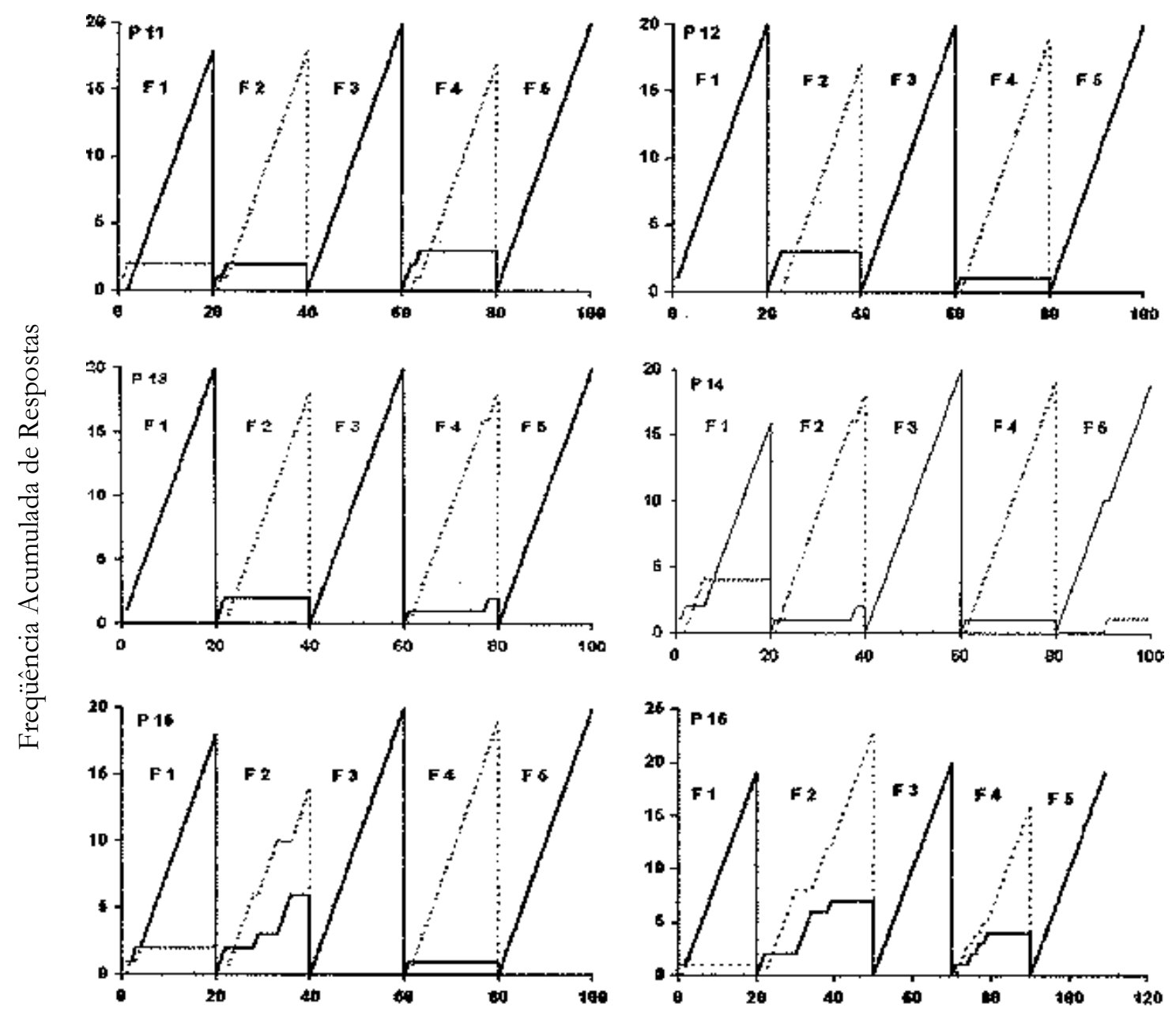

Tentativas

Figura 1. Freqüência acumulada de respostas de seguimento de instruções (linha sólida) e não seguimento de instruções (linha tracejada), para cada participante $(\mathrm{P})$ da Condição I, durante cada fase (F) experimental. Quebras na curva acumulada indicam mudanças de fase. As Fases 1, 2 e 3 eram iniciadas com instruções que correspondiam às contingências. Nas Fases 2 e 4, as instruções tornavam-se discrepantes das contingências. O observador estava presente na Fase 4. 
$\mathrm{Na}$ Fase 2, quando as contingências mudaram e o seguimento de instruções passou a produzir perda de fichas, todos os seis participantes abandonaram o seguimento de instruções. Ou seja, todos passaram a escolher o estímulo de comparação diferente do modelo na presença da luz verde e o estímulo de comparação igual ao modelo na presença da luz vermelha. Os Participantes P11 e P12 abandonaram o seguimento de instruções a partir da quarta tentativa. Os Participantes P13 e P14 abandonaram o seguimento de instruções a partir da terceira e segunda tentativas, respectivamente. Já P15 e P16 fizeram o mesmo a partir da décima sétima e da vigésima tentativa, respectivamente.

$\mathrm{Na}$ Fase 3, quando as instruções correspondentes foram reapresentadas, todos os participantes voltaram a seguir instruções.
Na Fase 4, quando as contingências foram novamente alteradas e o seguimento de instruções voltou a produzir perda de fichas, todos os seis participantes voltaram a abandonar o seguimento de instruções, independentemente da introdução do observador nesta fase. Os Participantes P11 e P12 abandonaram o seguimento de instruções a partir da quinta tentativa. Os Participantes P13, P14 e P15 abandonaram o seguimento de instruções a partir da segunda tentativa. Já o participante P16 abandonou o seguimento de instruções a partir da décima tentativa, portanto, mais cedo do que na Fase 2.

Na Fase 5, todos os participantes voltaram a seguir as instruções correspondentes apresentadas no início da fase.

A Figura 2 apresenta a freqüência acumulada de respostas de seguimento de instruções (linhas cheias) e não seguimento de instruções (linhas tracejadas) emitidas pelos Participantes
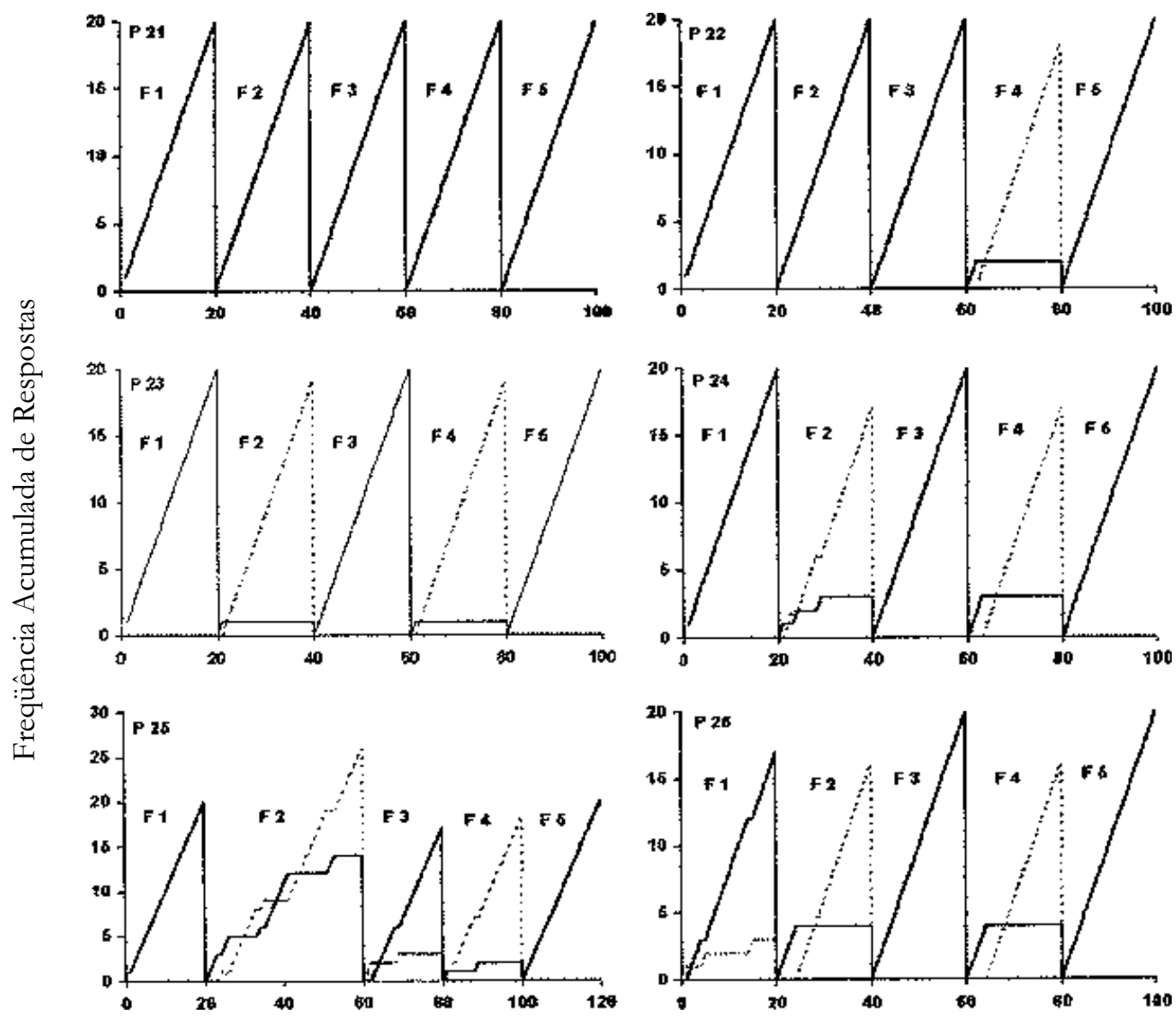

Tentativas

Figura 2. Freqüência acumulada de respostas de seguimento de instruções (linha sólida) e não seguimento de instruções (linha tracejada), para cada participante (P) da Condição II, durante cada fase (F) experimental. Quebras na curva acumulada indicam mudanças de fase. As Fases 1, 2 e 3 eram iniciadas com instruções que correspondiam às contingências. Nas Fases 2 e 4, as instruções tornavam-se discrepantes das contingências. O observador estava presente na Fase 2. 
P21, P22, P23, P24, P25 e P26 nas cinco fases da Condição II do experimento. Observa-se que todos os participantes (P21, P22, P23, P24, P25 e P26) seguiram a instrução apresentada no início da Fase 1. Apenas o Participante P26 emitiu respostas incorretas nesta fase, o que ocorreu na primeira, quinta e décima quinta tentativa.

$\mathrm{Na}$ Fase 2, quando as contingências foram alteradas, isto é, quando o seguimento de instruções passou a produzir perda de fichas e o observador foi introduzido na sala, dois participantes (P21 e P22) continuaram seguindo instruções, independentemente da mudança nas contingências programadas, e quatro participantes (P23, P24, P25 e P26) abandonaram o seguimento de instruções. Os Participantes P23 e P24 passaram a apresentar comportamento de acordo com as contingências programadas na Fase 2 a partir da segunda e da décima tentativa, respectivamente. O Participante P25 iniciou a Fase 2 seguindo instruções, entretanto, entre a quarta e a trigésima terceira tentativas apresentou um desempenho bastante variável, ora emitindo respostas corretas, ora emitindo respostas incorretas, razão pela qual a fase foi estendida até a redução da variabilidade. A partir da trigésima quarta tentativa abandonou totalmente o seguimento de instruções, passando a responder corretamente, de acordo com as contingências programadas para a fase. O Participante P26 abandonou o seguimento de instruções a partir da quarta tentativa.

$\mathrm{Na}$ Fase 3, quando as instruções correspondentes foram reapresentadas, cinco dos seis participantes (P21, P22, P23, P24 e P26) seguiram as instruções a partir da primeira tentativa. O Participante P25 seguiu as instruções a partir da segunda tentativa.

$\mathrm{Na}$ Fase 4, quando as contingências foram novamente alteradas e o seguimento de instruções voltou a produzir perda de fichas, cinco dos seis participantes (P22, P23, P24, P25, P26) abandonaram o seguimento de instruções. Isto é, mudaram seus desempenhos acompanhando a mudança nas contingências programadas, passando a apresentar respostas corretas. O Participante P21 foi o único que continuou seguindo as instruções apresentadas no início da Fase 3 durante toda a Fase 4.

$\mathrm{Na}$ Fase 5, todos os participantes seguiram as instruções apresentadas no início desta fase.

Em síntese, todos os seis participantes da Condição I (P11, P12, P13, P14, P15 e P16) seguiram as instruções correspondentes nas Fases 1, 3 e 5, quando o seguimento de instruções foi reforçado por evitar perda de reforçadores, e abandonaram o seguimento de instruções nas Fases 2 e 4, quando o seguimento de instruções passou a produzir perda de fichas, independentemente do seguimento de instrução ser (Fase 4) ou não (Fase 2) monitorado por um observador. Dos seis participantes da Condição II (P21, P22, P23, P24,
P25 e P26), todos seguiram as instruções correspondentes nas Fases 1, 3 e 5, replicando nestas fases os dados da Condição I. Quanto às Fases 2 e 4, em que as instruções tornavam-se discrepantes das contingências, quatro (P23, P24, P25 e P26) apresentaram um desempenho bastante similar ao apresentado pelos participantes da Condição I, abandonando o seguimento de instruções nas Fases 2 e 4; um (P21) seguiu instruções durante todas as cinco fases, independentemente das mudanças nas contingências programadas; e um (P22) seguiu instruções na Fase 2 (monitorada) e deixou de segui-las na Fase 4 (não monitorada).

\section{Discussão}

$\mathrm{Na}$ literatura sobre o comportamento governado por regras tem sido proposto que o seguimento de instruções tende a ser mantido quando é monitorado (Barret \& cols., 1987; Capovilla \& Hineline, 1989; Cerutti, 1994) e tende a deixar de ocorrer quando produz perda de reforçadores (Galizio, 1979; Paracampo \& cols., 1993). Os resultados de todos os participantes (P11, P12, P13, P14, P15 e P16) da Condição I do presente estudo também mostraram que, sob as condições do estudo, o seguimento de instruções deixou de ocorrer quando produziu perda de reforçadores. Em adição, mostraram que isto ocorreu mesmo quando o seguimento de instruções foi monitorado por um observador (nesse caso, introduzido na sala experimental na Fase 4), cuja função foi especificada pela apresentação de uma instrução. Em outras palavras, os resultados desses participantes sugerem que, mesmo quando é monitorado, o seguimento de instruções tende a deixar de ocorrer, quando produz perda de reforçadores. Esta sugestão também é apoiada pelos resultados dos Participantes P23, P24, P25 e P26 da Condição II do presente estudo, em que o observador entrava na sala experimental na Fase 2.

Os dados desses dez participantes (P11, P12, P13, P14, P15, P16, P23, P24, P25 e P26) que abandonaram o seguimento de instruções, quando comparados com os resultados de outros estudos que investigaram os efeitos da monitorização sobre o seguimento de instruções (Barret \& cols., 1987; Cerutti, 1994), poderiam sugerir também que é mais provável que a monitorização do seguimento de instruções possa contribuir para manter o comportamento de seguir instruções discrepantes das contingências quando o seguimento de instruções deixa de produzir reforço (caso dos estudos de Barret \& cols., 1987; Cerutti, 1994) do que quando passa a produzir perda de reforçadores (caso do presente estudo). De modo mais geral, poderiam sugerir que é mais provável que variáveis sociais que favorecem o seguimento de instruções interfiram na manutenção do seguimento de instruções quando as conseqüências produzidas pelo 
comportamento de seguir instruções são fracas (Ex.: não obtenção de pontos) do que quando são fortes (Ex.: perda de pontos). Esta análise é consistente tanto com a proposição que sugere que o seguimento de instruções é resultado da competição entre o controle por contingências sociais para o seguimento de instruções e o controle pelas conseqüências produzidas pelo seguimento de instruções (Hayes \& cols., 1986), quanto com a que sugere que o seguimento de instruções depende, em parte, da magnitude das conseqüências por ele produzidas (Cerutti, 1989; Galizio, 1979).

Contudo, para sustentar a sugestão de que é mais provável que variáveis sociais envolvidas no controle por instruções interfiram na manutenção do seguimento de instruções quando as conseqüências produzidas pelo comportamento de seguir instruções são fracas do que quando são fortes, seria necessário também avaliar que variáveis sociais seriam mais ou menos prováveis de favorecer o seguimento de instruções. Por exemplo, na literatura há evidências sugerindo que talvez a informação apresentada ao ouvinte, de que realmente o seu desempenho está sendo monitorado por alguém que é membro de uma classe generalizada de pessoas identificadas como "autoridades", seja uma variável mais importante na determinação do seguimento de instruções que a simples presença de um monitor. Por exemplo, há evidências mostrando que estudantes tendem a seguir mais instruções quando são informados que o experimentador é um professor do que quando são informados que o experimentador não é professor (Capovilla \& Hineline, 1989). Também há evidências mostrando que metas auto-estabelecidas são mais prováveis de serem seguidas quando são tornadas públicas do que quando não são divulgadas para outras pessoas (Hayes \& cols., 1985).

Assim, para investigar a competição entre o controle por variáveis sociais que podem favorecer o seguimento de instruções e o controle por diferentes tipos de conseqüências produzidas pelo seguimento de instruções discrepantes das contingências, seria necessário realizar novos estudos em que, por exemplo, em uma condição as instruções sobre o observador ou o experimentador fossem mantidas constantes e os tipos de conseqüências produzidas pelo seguimento de instruções fossem manipuladas, e em outra, as instruções sobre o observador ou o experimentador fossem manipuladas e os tipos de conseqüências produzidas pelo seguimento de instruções fossem mantidos constantes. Ou seja, seria necessário realizar estudos que manipulassem tanto a magnitude das variáveis sociais envolvidas no controle por instruções, quanto à magnitude das conseqüências produzidas pelo seguimento de instruções, e não apenas a magnitude destas últimas.
Em síntese, no presente estudo foram programadas condições tanto para favorecer o seguimento (presença do observador monitorando o seguimento de instruções), quanto para favorecer o não seguimento de instruções (perda de fichas trocáveis por brinquedos como conseqüência para o seguimento de instruções). $\mathrm{O}$ resultado (considerando os dados dos dez participantes que abandonaram o seguimento de instruções) foi que o controle pelas conseqüências imediatas produzidas pelo seguimento de instruções (perda de fichas) superou o controle pelas variáveis sociais para o seguimento de instruções (presença do observador). Em outras palavras, a presença do observador não foi suficiente para manter o seguimento de instruções quando as contingências mudaram e o comportamento mudou, deixando de ficar sob controle das instruções e passando a ficar sob controle das contingências programadas. Isto indica que o procedimento usado é bastante efetivo em produzir comportamento sob controle das contingências, isto é, em produzir comportamento que muda de acordo com a mudança nas contingências, mesmo quando isto implica em deixar de seguir instruções. Contudo, isto não implica em dizer que, sob outras condições, o controle por variáveis sociais envolvidas no seguimento de instruções não possa prevalecer sobre o controle pelas conseqüências produzidas pelo seguimento de instruções, mesmo quando estas forem perda de reforçadores. Os dados dos dois participantes que seguiram instrução, mesmo quando o seguimento de instrução produzia perda de reforçadores, indicam que esta possibilidade não deveria ser descartada, mas sim, investigada.

\section{Referências}

Albuquerque, L. C. (1998). Efeitos de histórias experimentais sobre o seguimento subseqüente de regras. Tese de Doutorado não-publicada, Instituto de Psicologia, Universidade de São Paulo. São Paulo: SP.

Albuquerque, L. C. \& Ferreira, K. V. D. (2001). Efeitos de regras com diferentes extensões sobre o comportamento humano. Psicologia: Reflexão e Crítica, 14, 127-139.

Baron, A. \& Galizio, M. (1983). Instructional control of human operant behavior. The Psychological Record, 33, 495-520.

Baron, A., Kaufman, R. \& Stauber, K. A. (1969). Effects of instructions and reinforcement-feedback on human operant behavior maintained by fixedinterval reinforcement. Journal of the Experimental Analysis of Behavior, 12, 701-712.

Bernstein, D. J. (1988). Laboratory lore and research practices in the experimental analysis of human behavior: Designing session logistics-how long, how often, how many? The Behavior Analyst, 11, 51-58.

Barret, D. H., Deitz S. M., Gaydos G. R. \& Quinn, P. C. (1987). The effects of programmed contingencies and social conditions on responses stereotipy with human subjects. The Psychological Record, 34, 489-505.

Capovilla, F. C. \& Hineline, P. N. (1989). Efeitos da fonte da instrução, do formato da instrução e das relações entre as demandas da instrução e da tarefa [Resumos]. Em Sociedade de Psicologia de Ribeirão Preto (Org.), Anais, XIX Reunião Anual de Psicologia da Sociedade de Psicologia de Ribeirão Preto (p. 87). Ribeirão Preto, SP: SPRP. 
Cerutti, D. T. (1989). Discrimination theory of rule-governed behavior. Journal of the Experimental Analysis of Behavior, 51, 259-276.

Cerutti, D. T. (1994). Compliance with instructions: Effects of randomness in scheduling and monitoring. The Psychological Record, 41, 51-67.

Chase, P. N. \& Danforth, J. S. (1991). The role of rules in concept learning. Em L. J. Hayes \& P. N. Chase (Orgs.), Dialogues on verbal behavior (pp. 205-225). Hillsdale, NJ: Erlbaum.

Galizio, M. (1979). Contingency-shaped and rule-governed behavior: Instructional control of human loss avoidance. Journal of the Experimental Analysis of Behavior, 31, 53-70.

Hayes, S. G., Brownstein, A. J., Zettle, R. D., Rosenfarb, I. \& Korn, Z. (1986). Rule-governed behavior and sensitivity to changing consequences of responding. Journal of the Experimental Analysis of Behavior, 43, 237-256.

Hayes, S. C., Rosenfarb, I., Wulfert, E., Munt, E., Korn, Z. \& Zettle, R. D. (1985). Self reinforcement effects: An artifact of social standard setting. Journal of Applied Behavior Analysis, 18, 201-214.

Hayes, S. C. \& Wolf, M. R. (1984). Cues, consequences and therapeutic talk: Effects of social context and coping statements on pain. Behavior Research and Therapy, 22, 385-392.

Joyce, J. H. \& Chase, P. N. (1990). Effects of response variability on the sensivity of rule-governed behavior. Journal of the Experimental Analysis of Behavior, 54, 251-262.

LeFrancois, J. R., Chase, P. N. \& Joyce, J. (1988). The effects of variety of instructions on human fixed-interval performance. Journal of the Experimental Analysis of Behavior, 49, 383-393.

Lippman, L. G. \& Meyer, M. E. (1967). Fixed interval performance as related to instructions and to subjects' verbalizations of the contingency. Psychonomic Science, 8, 135-136.

Michael, R. L. \& Bernstein, D. J. (1991). Transient effects of acquisition history on generalization in a matching-to-sample task. Journal of the Experimental Analysis of Behavior, 56, 155-166.

Paracampo, C. C. P. (1991). Alguns efeitos de estímulos antecedentes verbais e reforçamento programado no seguimento de regra. Psicologia: Teoria e Pesquisa, 7,149-161.
Paracampo, C. C. P., Albuquerque, L. C. \& Fontes, J. C. S. (1993). Análise de algumas das variáveis responsáveis pela manutenção do seguimento de regras [Resumos]. Em Sociedade Brasileira para o Progresso da Ciência (Org.), Anais, $45^{a}$ reunião anual da Sociedade Brasileira para o Progresso da Ciència (p. 984). Recife, PE: SBPC.

Paracampo, C. C. P., Souza, D. G., Matos, M. A. \& Albuquerque, L. C. (2001). Efeitos de mudança em contingências de reforço sobre o comportamento verbal e não-verbal. Acta Comportamentalia, 9, 31-55.

Perone, M., Galizio, M. \& Baron, A. (1988). The relevance of animal-based principles in the laboratory study of human operant conditioning. Em G. Davey \& C. Cullen (Orgs.), Human operant conditioning and behavior modification (pp. 59-85). New York: Wiley.

Peterson, R. F., Merwin, M. R., Moyer, T. J. \& Whitehurst G. J. (1971). Generalized imitation: The effects of experimenter absence, differential reinforcement, and stimulus complexity. Journal of Experimental Child Psychology 12, 114128.

Rosenfarb, I. \& Hayes S. C. (1984). Social standard setting: The achilles heel of informational accounts of therapeutic change. Behavior Therapy, 15, 515-528.

Shimoff, E., Catania, A. C. \& Matthews B. A. (1981). Uninstructed human responding: Sensitivity of low-rate performance to schedule contingencies. Journal of the Experimental Analysis of Behavior, 36, 207-220.

Torgrud, L. J. \& Holborn, S. W. (1990). The effects of verbal performance descriptions on nonverbal operant responding. Journal of the Experimental Analysis of Behavior, 54, 273-291.

Zettle, R. D. \& Hayes, S. C. (1983). Effect of social context on the impact of coping self-statements. Psychological Reports, 52, 391-401.

Weiner, H. (1970). Instructional control of human operant responding during extinction following fixed-ratio conditioning. Journal of the Experimental Analyses of Behavior, 13, 391-395.

Sobre os autores

Niele Márcia Amaral de Albuquerque é Mestre em Teoria e Pesquisa do Comportamento.

Carla Cristina Paiva Paracampo é Professora do Departamento de Psicologia Experimental da Universidade Federal do Pará e do Programa de Pós-Graduação em Teoria e Pesquisa do

Comportamento da mesma instituição.

Luiz Carlos de Albuquerque é Professor do Departamento de Psicologia Experimental da Universidade Federal do Pará e Coordenador do Programa de Pós-Graduação em Teoria e Pesquisa do Comportamento da mesma instituição. 